\title{
CONSERVAÇÃO DE SEMENTES PRÉGERMINADAS DE ORQUÍDEAS TROPICAIS EM CRIOCONGELAMENTO
}

\author{
Leandro Haruo Sawamura, Nelson Barbosa Machado Neto, Silvério Takao Hosomi \\ Universidade do Oeste Paulista - UNOESTE, Programa de Pós-Graduação em Agronomia, Presidente Prudente - SP. E- \\ mail: leandrosawamura@gmail.com, nbmneto@unoeste.br
}

\section{RESUMO}

O estabelecimento de bancos de sementes é fundamental para a conservação de espécies de orquídeas, todavia, as informações para armazenamento de orquídeas são limitadas, quanto ao que são consideradas condições mais adequadas. Sementes germinadas armazenadas a temperatura de nitrogênio líquido $\left(-196^{\circ} \mathrm{C}\right)$ podem ser uma opção. O presente estudo visou avaliar o efeito do tempo de exposição e de três crioprotetores no condicionamento para crioconservação à $-196^{\circ} \mathrm{C}$ de sementes pré germinadas de Cattleya intermedia, $C$. milleri e $C$. warnerii nos tempos: 0, 1, 3, 6 e 24 horas de condicionamento nos crioprotetores. Os testes realizados foram o Teste de Tetrazólio e o Teste da Sobrevivência das Sementes. Os resultados obtidos não se mostraram eficazes para as presentes espécies estudadas. No entanto, de acordo com a literatura, para algumas espécies tropicais de orquídeas já foi possível realizar a criopreservação de sementes pré-germinadas.

Palavras chave: Crioconservação, crioprotetores, sobrevivência, Orchidaceae, Cattleya.

\section{SEEDLINGS CONSERVATION OF TROPICAL ORCHIDS IN CRYOPRESERVATION}

\begin{abstract}
The establishment of seed banks is essential to the conservation of species of orchids, however, information storage orchids are limited as to what are considered more suitable conditions. Germinated seeds stored at liquid nitrogen temperature $\left(-196^{\circ} \mathrm{C}\right)$ can be an option. This study aimed to evaluate the effect of exposure time and three cryoprotectants in cryopreservation at $196^{\circ} \mathrm{C}$ for conditioning pre germinated seeds of Cattleya intermedia, C. milleri and C. warnerii at times: 0, 1, 3, 6 and 24 hours conditioning in cryoprotectants. Tests included the Tetrazolium Test and the Test of Survival Seed. The results were not effective for these species. However, according to the literature, for some tropical species of orchids has been possible to achieve cryopreservation pre-germinated seeds.
\end{abstract}

Keywords: Cryopreservation, cryoprotector, survival, Orchidaceae, Cattleya

\section{INTRODUÇÃO}

As orquídeas representam o maior grupo entre as angiospermas em número, estima-se que existem entre 20.000 a 35.000 espécies, distribuídas em 775 gêneros (JUDD et al. 2009) sendo que, no Brasil, existem cerca de 2.419 espécies das quais 1.620 são endêmicas deste país (DRESSLER 2005; SOUZA; LORENZI 2008), ocorrendo em quase todos os ecossistemas da terra, embora seja mais abundante e diversificada em florestas tropicais (NIKISHINA et al. 2001, 2007). 
Algumas espécies têm grande importância econômica, um exemplo é a essência de baunilha extraída dos frutos de Vanilla planifolia; algumas outras espécies possuem alto valor ornamental, como por exemplo, as Cattleyas, Phalaenopsis, Dendrobium entre outras (JUDD et al. 2009).

Conforme Primack, 2001, existem dois tipos de conservação de fauna e flora, sendo elas: Conservação ex situ, quando se trata da manutenção de indivíduos em condições artificiais fora do seu habitat de origem e sob a supervisão humana a fim de evitar a extinção das espécies, como é o caso de: bancos de sêmen, jardins zoológicos, aquários, fazendas de criação de animais, programas de criação em cativeiro, jardins botânicos, viveiros, arboretos e germoplasma.

Outra forma de conservação é in situ, que se trata da preservação dos ecossistemas e dos habitats naturais, garantindo a manutenção de populações em seu habitat natural, como em áreas de proteção ambiental. Esse método de conservação apresentam algumas vantagens, tais como: favorecer a proteção e a manutenção da vida silvestre, permitir que as espécies continuem seus processos evolutivos, conservar as relações biológicas envolvidas com os indivíduos, como os polinizadores e dispersores de sementes (PRIMACK, 2001).

O estabelecimento de bancos de sementes é fundamental para a conservação das espécies cultivadas e silvestres (ALVAREZ-PARDO; FERREIRA 2006; SEATON; PRITCHARD 2008). As informações para armazenamento de sementes de orquídeas são limitadas, e ainda há algumas divergências entre autores quanto ao que são consideradas condições mais adequadas (SHOUSHTARI et al. 1994; PRITCHARD; SEATON 1993; PRITCHARD et al.1999; MACHADO NETO; CUSTÓDIO 2005a, SEATON; PRITCHARD 2008). Algumas podem ter duração curta, apenas três meses, quando armazenadas secas a $4^{\circ} \mathrm{C}$ (MACHADO NETO; CUSTÓDIO 2005b), enquanto o armazenamento em temperatura mais baixa (sub-zero, $-18^{\circ} \mathrm{C}$ ) é considerado mais adequado para armazenamento de longo prazo (SEATON; PRITCHARD 2008).

De acordo com Ernst e Arditti, 1990 apud Galdiano Júnior et al. (2010), na natureza, a germinação das sementes de orquídeas está associada a fungos micorrízicos, devido ao diminuto tamanho das sementes e a baixa reserva nutricional. Em virtude disso, muitas espécies apresentam baixo sucesso reprodutivo ou habitat restrito, portanto, a importância da conservação in vitro das sementes das orquídeas.

Apesar de algumas orquídeas, ameaçadas de extinção, poderem ser propagadas em meio apropriado in vitro a partir de sementes (LONG et al. 2010; DUTRA et al. 2009; ÁVILA-DIAZ et al. 2009, HOSOMI et al. 2012), esta não é uma estratégia fácil de seguir para todos os taxa. Além disso, as sementes de algumas espécies não podem ser armazenadas a baixa temperatura e umidade, pois expressam características intermediárias ou recalcitrantes, uma vez que não 
toleram dessecação, ou armazenamento em condições de câmara fria (MACHADO NETO; CUSTÓDIO 2005b), por não se apresentarem como ortodoxas clássicas (ELLIS; HONG 2007). Como alternativa, bancos de semente têm o potencial de longo prazo de armazenamento de um grande número de propágulos (IUCN 1996, MACHADO NETO; CUSTÓDIO 2005b), o que seria facilitado em orquídeas, pois como as sementes destas são pequenas, cada cápsula pode conter de centenas a milhões de sementes (ARDITTI; GHANI 2000).

A criopreservação pode ser uma alternativa para plantas que apresentem sementes recalcitrantes, que não tolerem dessecação ou diminuição de temperatura. Neste caso, a estocagem de embriões seria a alternativa, em ultracongelamento $\left(-80^{\circ} \mathrm{C}\right)$ ou criocongelamento (BENSON 2008).

Em orquídeas, alguns experimentos já foram conduzidos com pólen (VENDRAME et al. 2008), sementes (THAMASIRI 2000, WANG et al. 2011) ou com embriões (NIKISHINA et al. 2001, 2007) com resultados promissores. Todavia, alguns resultados obtidos por este grupo demonstram que embriões em estágio 1 (SEATON; HAILES; 1989) são pouco tolerantes à crioconservação (dados não publicados).

De acordo com CROWE et al. (1988) estruturas acumuladoras de açúcares, como sementes e pólen, na maioria das angiospermas, apresentam tolerância a crioconservação. Todavia, sementes de orquídeas apresentam reservas lipídicas o que poderia tornar mais difícil a conservação deste tipo de sementes por meio de crioconservação. A remoção da água, por meio de crioprotetores químicos que ocasionam a vitrificação do citoplasma e das membranas é uma alternativa para isto.

Alguns crioprotetores utilizados são à base de DMSO (dimetilsulfóxido), etilenoglicol, metanol, glicerol e propileno-glicol, todavia a exposição prolongada a estes materiais pode ser danosa, pois segundo Kartha (1985) e Sakai (1995) essas soluções possuem alta citotoxidade e podem acarretar a morte celular. Neste ponto, os açucares também são considerados agentes vitrificadores, sendo utilizados como crioprotetores e mostrando eficiente estabilidade na membrana celular durante o congelamento. O efeito protetor dos açucares como a trehalose, sacarose e glucose pode estar associado à vitrificação das membranas citoplasmáticas (HIRSH 1987; KOSTER 1991; LEOPOLD 1990). Sementes de orquídeas pré condicionadas com sacarose forma mais responsivas ao tetrazólio que sementes secas pré condicionadas com água (HOSOMI et al. 2011).

De acordo com PIÑA-RODRIGUES et al. (2004) apud Hosomi et al (2011), para avaliar de forma rápida a viabilidade, qualidade e vigor dos embriões de orquídeas é utilizado o teste 
bioquímico de tetrazólio, que consiste na reação do reagente 2,3,5 trifenil cloreto de tetrazólio com células envolvidas na respiração celular, o que torna possível distinguir as partes vivas que se apresentam coradas em vermelho daquelas mortas, que mantêm sua coloração original.

O presente estudo visou avaliar o efeito do tempo de exposição e de três crioprotetores no condicionamento para crioconservação à $-196 \circ \mathrm{C}$ de sementes pré germinadas de Cattleya intermedia, C. milleri e C. warnerii nos tempos: 0, 1, 3, 6 e 24 horas de condicionamento nos crioprotetores.

\section{MATERIAL E MÉTODOS}

Sementes

As cápsulas foram obtidas por polinização cruzada com plantas de diferentes origens. 0 processo de colheita foi realizado em períodos diferentes para acomodar os tempos de maturação. Os frutos foram deixados em sacos de papel e mantidos sob condições ambientais até deiscência completa. As sementes de cada espécie foram limpas, colocadas em sacos de papel fino até atingirem equilíbrio higroscópico sobre uma solução saturada de cloreto de lítio a 25 C por uma semana alcançando entre 6 a 6,5\% de teor de água. O grau de umidade foi aferido gravimetricamente com 3 repetições de $20 \mathrm{mg}$ colocados em tubos de $200 \mu \mathrm{L}$ e deixados em estufa a 105ㄷ $\mathrm{C}$ por 24h (BRASIL 2009).

A germinação foi realizada em duas condições de meio semi-sólido MS (MURASHIGE; SKOOGE; 1962). Os meios foram preparados normalmente com o pH ajustado para 5,6 (com $\mathrm{NaOH})$. Um dos meios continha a concentração normal de sacarose $\left(20 \mathrm{gL}^{-1}\right)$ e o outro continha $0,3 \mathrm{M}$ do mesmo açúcar $\left(102,9 \mathrm{gL}^{-1}\right)$ e $10 \mathrm{~g}$ de ágar $\mathrm{L}^{-1}$. Os meios foram autoclavados e dispensados em Placas de Petri. Antes da semeadura, $10 \mathrm{mg}$ de cada lote de sementes foram desinfetados com uma solução de dicloroisocianurato de sódio (NaDCC; $5 \mathrm{~g} . \mathrm{L}^{-1}$ ) contendo $100 \mu \mathrm{l}$ de Tween 80, por 10 minutos. As sementes foram lavadas duas vezes com água destilada estéril e colocadas no meio. A semeadura foi realizada em uma capela de fluxo laminar de acordo com Machado Neto e Custódio (2005a). Três placas foram usadas por espécie, seladas com filme de PVC e transferidas para uma sala de crescimento a $25 \pm 3$ 으 com fotoperíodo $16 \mathrm{~h}$.

Para os ensaios dos embriões germinados de Cattleya intermedia, C.warnerii, C. milleri foram coletados e limpos de debris e sementes mortas por centrifugação diferencial em sacarose e submetidas ao pré-condicionamento com os crioprotetores.

Os crioprotetores utilizados no experimento foram:

1. D.S.G com $7,81 \%$ DMSO, $9,21 \%$ glicerol e $62,45 \%$ sacarose 
2. PVS2 com $30 \%$ de glicerol, $15 \%$ de DMSO, $15 \%$ de etilenoglicol;

3. PVS3 com $40 \%$ de glicerol, $40 \%$ de sacarose;

Todos adicionados de $1 \mathrm{~mL}$ dos estoques do meio MS (MURASHIGE; SKOOGE; 1962), totalizando 7 $\mathrm{mL}$, mais $2 \mathrm{~g}$ de sacarose e completados para $100 \mathrm{~mL}$ com água destilada.

As sementes germinadas foram mantidas nesta mistura, por $0,1,3,6$ e 24 horas a $25 \pm 3$ 으. As mesmas foram aliquotadas em tubos criogênicos, e mantidas em nitrogênio líquido por período de 5 minutos. Uma parte das sementes foi testada para tetrazólio para confirmar a viabilidade (HOSOMl et al., 2011).

Passado cada período de estocagem, um frasco de cada tratamento foi retirado, descongelado à 43 으 e os embriões, lavados em meio líquido e colocados para crescer em meio de cultura MS solidificado com agar $\left(6 \mathrm{gL}^{-1}\right), \mathrm{pH} 5,6$.

Teste de Tetrazólio

Para realização do teste de tetrazólio foi necessário deixar os embriões em solução de $10 \%$ de sacarose por 24 horas em temperatura ambiente. Em seguida foi feita a troca da solução pela solução aquosa de tetrazólio a 1\%, também em 24 horas e em temperatura de 40 으. Para realização do teste de tetrázolio foi necessário o auxílio de um microscópio esteroscópio, com aumento final de 40 vezes, o qual, os embriões corados de vermelho estão viáveis, os que não apresentam coloração avermelhada não estão viáveis.

\section{RESULTADOS}

O uso de crioprotetores em sementes de orquídeas já foi realizado em sementes (THAMASIRI 2000, WANG et al. 2011) ou com embriões (NIKISHINA et al. 2001, 2007), com relativo sucesso em outras espécies que não o gênero Cattleya.

Em resultados preliminares, deste grupo, os crioprotetores utilizados foram testados para sementes e permitiram aferir que as sementes secas com $6 \%$ de teor de água, já apresentavam condições suficientemente boas para serem crioconservadas, sendo superior este tratamento aos crioprotetores (HENGLING, 2012). Todavia, algumas espécies não toleram o processo convencional de armazenamento (MACHADO-NETO; CUSTÓDIO 2005a) sendo necessário buscar alternativas diferentes de armazenamento para este tipo de material.

Apesar deste tipo de técnica ser utilizada com relativa facilidade para sementes ricas em açúcares, nem sempre logra sucesso em sementes ricas em óleo como é o caso das orquídeas (ARDITTI e GHANI, 2000) 
Ao serem retirados do nitrogênio líquido, os protocórmios foram descongeladas em água à

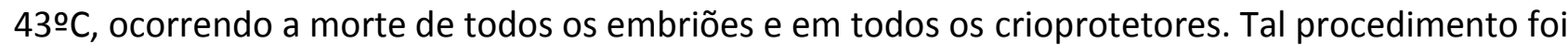
adotado por propiciar um descongelamento mais rápido e evitar a formação dos cristais de água no interior da célula. Em um projeto anterior os embriões foram descongelados a temperatura de 40 ㄷ C e 45C e também não lograram êxito.

As sementes germinadas no meio de cultura com $0,3 \mathrm{M}$ de sacarose não se desenvolveram em embriões para o posterior congelamento, ao contrário das sementes germinadas no meio de cultura MS normal com $20 \mathrm{gL}^{-1}$ de sacarose que se desenvolveram, chegaram a fase de embrião, porém, não suportaram o nitrogênio líquido.
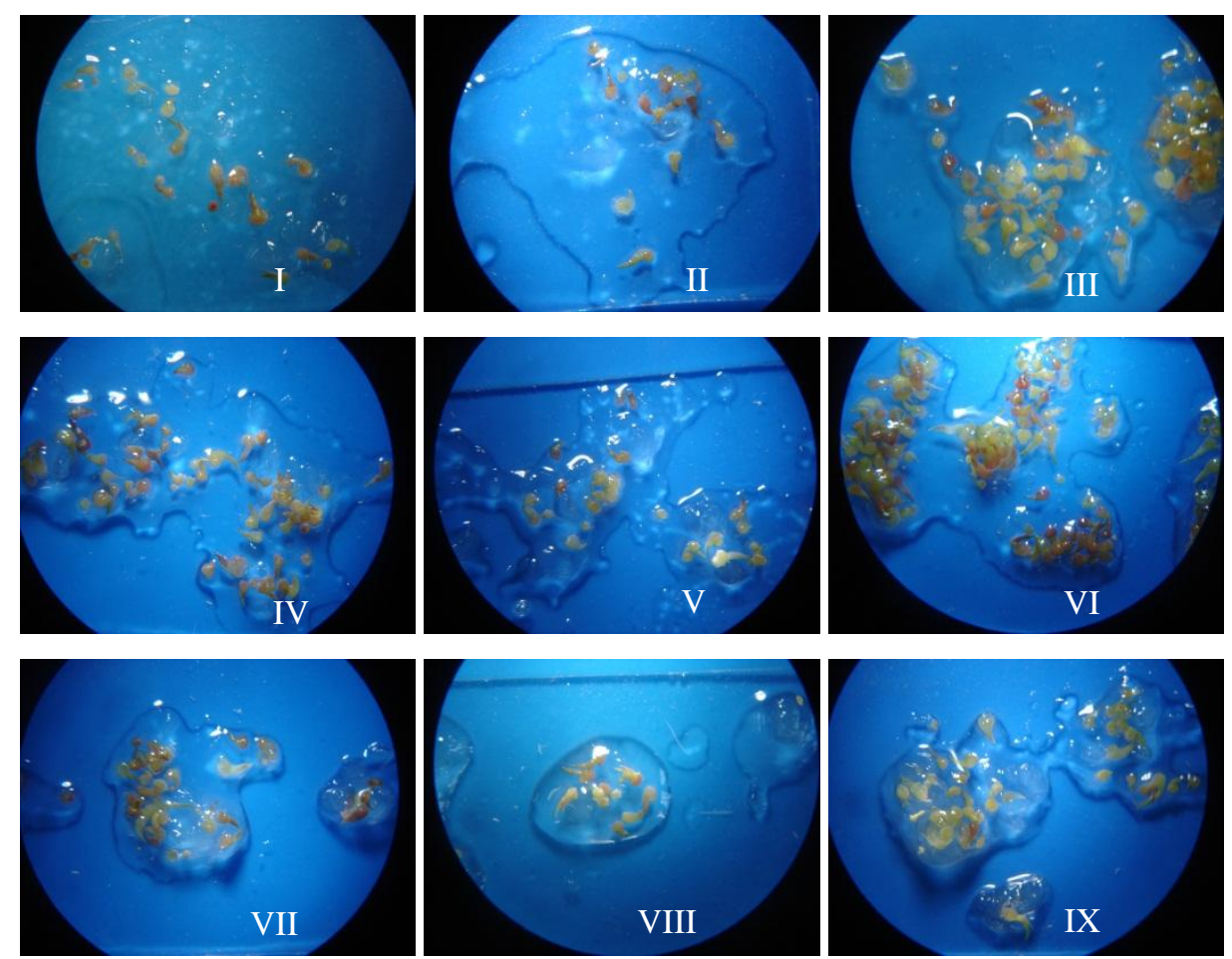

Figura 1. Fotografias dos embriões de Cattleya intermedia submetidos ao teste de tetrazólio antes da criopreservação, observados no microscópio óptico com aumento 40 vezes. I - Embriões após o tratamento com o crioprotetor GSD no período de 0 hora. II - Embrião após o tratamento com GDS no período de 3 horas. III - Embrião após o tratamento com GDS no período de 6 horas. IV Embrião após o tratamento com o crioprotetor PVS2 no período de 0 hora. V - Embrião após o tratamento com PVS2 no período de 3 horas. VI - Embrião após o tratamento com PVS2 no período de 6 horas. VII - Embrião após o tratamento com o crioprotetor PVS3 no período de 0 hora. VIII - Embrião após o tratamento com PVS3 no período de 3 horas. IX - Embrião após o tratamento com PVS3 no período de 6 horas. 


\section{CONCLUSÕES}

O processo de crioconservação não foi homogêneo para as espécies estudadas. Mesmo baseando-se em um protocolo pré-existente, este não funcionou para estes materiais.

De acordo com as imagens do Teste de Tetrazólio, foi possível perceber que os crioprotetores já se apresentam com elevada toxidade, danificando os tecidos vegetais. Logo após, ao sofrer um estresse ainda maior, o qual é o nitrogênio líquido, os embriões não sobrevivem.

\section{REFERÊNCIAS}

ALVAREZ-PARDO, V.; FERREIRA, A.G. Armazenamento de sementes de orquídeas. Rev Bras Sementes, 28:92-98, 2006. http://dx.doi.org/10.1590/S0101-31222006000100013

CROWE, J.H.; OLIVER, A.E.; HOEKSTRA, F.A. \& CROWE, L.M. Stabilization of dry membranes by mixtures of hydroxyethyl starch and glucose: the role of vitrification. Cryobiology, 35: 20-30, 1997. DRESSLER, R.L. How Many Orchids Species. Selbyana 26:155-158, 2005. http://dx.doi.org/10.1006/cryo.1997.2020

DUTRA, D.; KANE, M.E.; RICHARDSON, L. Asymbiotic seed germination and in vitro seedling development of Cyrtopodium punctatum: a propagation protocol for an endangered Florida native orchid. Plant Cell Tiss Organ Cult 96:235-243, 2009. http://dx.doi.org/10.1007/s11240-008$\underline{9480-z}$

HOSOMI, S.T.; CUSTODIO, C.C.; SEATON, P.T.; MARKS, T.R.; MACHADO-NETO, N.B. Improved assessment of viability and germination of Cattleya (Orchidaceae) seeds following storage. In Vitro Cell.Dev.Biol._Plant, 48:127-136, 2012. http://dx.doi.org/10.1007/s11627-011-9404-1

JUDD, W.S.; STEVENS, P.F.; KELLOG, E.A.; DONOGHUE, M.J.; CAMPBELL, C.S. Sistemática vegetal: um enfoque filogenético. 3.ed. Porto Alegre: Artmed, 2009.

MACHADO-NETO, N.B.; CUSTODIO, C.C. A medium for non-commercial sowing of orchid seed. Selbyana 26:316-317, 2005a.

MACHADO-NETO, N.B.; CUSTODIO, C.C. Orchid conservation through seed banking: ins and outs. Selbyana 26:229-235, 2005b.

MURASHIGE, T.; SKOOG, F. A revised medium for rapid growth and bio-arsays with tabacco tissue cultures. Physiologia Plantarum, v.15, p.473-497, 1962. http://dx.doi.org/10.1111/i.13993054.1962.tb08052.x

NIKISHINA, T.V.; POPOV, A.S.; KOLOMEITSEVA, G.L.; GOLOVKIN, B.N. Cryopreservation of Seeds and Protocorms of Rare Temperate Orchids. Russ J Plant Physiol, 54:121-127, 2007. http://dx.doi.org/10.1134/S1021443707010189

NIKISHINA, T.V.; POPOVA, E.V.; VAKHRAMEEVA, M.G.; VARLYGINA, T.I.; KOLOMEITSEVA, G.L.; BUROV, A.V.; POPOVICH, E.A.; SHIROKOV, A.I.; SHUMILOV, V.Y.U.; POPOV, A.S. Cryopreservation 
of Seeds of Some Tropical Orchids. Doklady Biochem and Biophy, 378:231-233, 2001. http://dx.doi.org/10.1023/A:1011585801668

SAKAI, A. Cryopreservation of germplasm of woody plants. In: Bajaj YPS. (Ed.) Biotechnology in agriculture and forestry. vol 32. Cryopreservation of plant germplasm I. Berlin, Heidelberg, New York, Springer-Verlag, 1995. pp 53-69. 